\title{
KAJI NUMERIK PENCEGAHAN PERTUMBUHAN RETAK DENGAN MENGGUNAKAN METODE MODIFIKASI BENTUK STOP-DRILLED HOLE (SDH)
}

\author{
Yudi Dwianda, Hendery Dahlan, Meifal Rusli \\ Jurusan Teknik Mesin, Universitas Andalas \\ Kampus Limau Manis, Padang, Sumatera Barat \\ Email: henderydahlan@ft.unand.ac.id
}

\begin{abstract}
ABSTRAK
Salah satu mekanisme kegagalan yang utama dalam aplikasi teknik atau komponen mesin adalah penjalaran retak kelelahan. Penjalaran retak ini biasanya dimulai dari titik-titik pada daerah yang mengalami konsentrasi tegangan yang tinggi. Oleh karena itu salah satu metode untuk menghambat penjalaran retak adalah mereduksi konsentrasi tegangan dimana salah satu metode yang digunakan adalah pemberian lubang di ujung retak atau dikenal dengan stop-drilled hole (SDH). Pada penelitian ini akan dikembangkan modifikasi bentuk model SDH. Pada dasarnya model yang dikembangkan ini adalah mengubah bentuk pada sisi lubang agar tidak berbentuk lengkungan sehingga konsentrasi tegangan menurun di daerah tersebut. Pemodelan lubang yang dikembangkan pada penelitan ini adalah penggabungan dua lubang dan tiga lubang pada ujung retak. Pada penelitian ini akan dilakukan penghitungan faktor konsentrasi tegangan untuk variasi jari-jari lubang yang diberikan. Dari penelitian yang telah dilakukan dapat disimpulkan bahwa pemberian dua lubang dan tiga lubang pada ujung cetak tersebut dapat mereduksi faktor konsentrasi tegangan dengan signifikan, nilai faktor konsentrasi tegangan antara dua lubang dan tiga lubang tidak berbeda signifikan terutama dengan meningkatnya nilai jari-jari lubang. Sementara itu, faktor konsentrasi tegangan tetinggi terjadi pada daerah perubahan geometri pada lubang untuk pemberian dua atau tiga lubang, akan tetapi faktor konsentrasi tegangannya masih cukup rendah jika dibandingkan dengan pemberian satu lubang.
\end{abstract}

Kata Kunci: Konsentrasi tegangan, penjalaran retak, stop-drilled hole (SDH)

\begin{abstract}
One of the major failure mechanisms in engineering applications or machine components is the propagation of fatigue cracking. The spreading of these cracks usually are started from the points on the regions that are experiencing high stress concentrations. Therefore, one of the method to inhibit this crack propagation is reducing the stress concentration in which one of the used methods is the provision of a hole at the end of a crack or known as a stop-drilled hole (SDH). In this research will be developed a modification form of SDH model. Basically the developed model is changing the shape on the hole side so there are not forming of the curve so that the stress concentration decreases in this area. The developed hole model in this research is the binding of two holes and three holes at the crack tip. This research will be calculated the stress concentration factor for variation of given hole radius. From the research that has been done, it can be concluded that the two holes and three holes on
\end{abstract}


the tip of the crack can reduce the stress concentration factor significantly. Moreover, the value of the stress concentration factor between two holes and three holes is not significantly different, especially with the increment of the hole radius. Meanwhile, the high stress concentration factor occured in the geometrical change area of the hole for two or three holes, but the stress concentration factor is still quite low when compared to the one hole.

\section{Keywords: Stress Concentration, Crack Propagation, Stop-Drilled Hole (SDH)}

\section{PENDAHULUAN}

Salah satu mekanisme kegagalan yang utama dalam aplikasi teknik atau komponen mesin adalah penjalaran retak kelelahan. Penjalaran retak ini biasanya dimulai dari titiktitik pada daerah yang mengalami tegangan terkonsentrasi. Konsentrasi tegangan yang lebih tinggi dari nilai kritis materialnya menyebabkan retak terus tumbuh sehingga menyebabkan kegagalan pada komponen mesin. Oleh karena itu, diperlukan suatu metode yang efektif untuk menahan pertumbuhan retak sebelum kegagalan terjadi pada komponen mesin.

Sejumlah penelitian telah dilakukan untuk menahan penjalaran retak kelalahan. Salah satu teknik yang paling populer adalah mengebor lubang di ujung retak untuk menghilangkan singularitas tegangan ujung retak. Metode ini disebut stop-drilled hole (SDH) [1]. Mekansime metode ini mengakibat pertumbuhan retak tertunda atau berhenti sampai retakan baru dimulai. Berberapa modifikasi metode SDH telah dilakukan dengan membuat lubang tambahan dimsekitar daerah ujung retak [2,3], lubang tambahan dengan memasukan pin di dalamnya [4] dan membuat double hole di ujung retak [5].

Pada penelitian ini akan dikembangkan metode SDH yang konsepnya hampir sama dengan double hole [5] tetapi dengan memodifikasi bentuk SDH. Metode ini bertujuan untuk mereduksi konsentrasi tegangan pada sisi lubang, sehingga retak tidak tumbuh dan menjalar.

\section{TEORI DAN PEMODELAN}

Jika sebuah spesimen pelat yang memliki panjang $\mathrm{w}$ dan tinggi $2 \mathrm{H}$ mempunyai celah (slit) sepanjang a yang terletak sejauh $\mathrm{H}$ dari atas permukaan pelat mengalami pembebanan $\sigma_{\mathrm{o}}$, maka faktor konsentrasi tegangan $\left(\mathrm{K}_{\mathrm{t}}\right)$ pada ujung celah (titik $\mathrm{A}$ ) dapat dihitung berdasarkan persamaan berikut:

$$
\mathrm{K}_{\mathrm{t}}=\sigma_{\max } / \sigma_{\mathrm{o}}
$$

Dimana $\sigma_{\max }$ adalah tegangan maksimum pada titik A dan $\sigma_{\mathrm{o}}$ adalah tegangan yang diberikan pada spesimen pelat seperti diperlihatkan pada gambar 1 .

Konsentrasi tegangan yang sangat tinggi akan menyebabkan munculnya retak dan jika pembebanan terus dilanjutkan maka retak akan menjalar dan selanjutnya akan terjadi kegagalan (patah). Untuk mereduksi konsentrasi tegangan tersebut maka dilakukan pemberian lubang di ujung retak dengan jari-jari R seperti terlihat pada gambar 2.a. Diketahui bahwa hubungan antara konsentarsi tegangan dengan jari-jari lubang adalah semakin besar jari-jari lubang yang diberikan maka konsentrasi tegangan yang diberikan akan menurun, akan tetapi dengan terbatas lebar pelat (w), jika pemberian jari-jari lubang yang terlalu besar, maka akan menyebabkan lebar pelat yang tidak memliliki celah kecil sehingga akan menyebabkan pelat mudah untuk mengalami kegagalan (patah). Oleh karena itu dikembangkan model lubang yang telah dimodifikasi. Pada dasarnya model yang dikembangkan ini adalah untuk mereduksi konsentrasi tegangan pada sisi lubang (titik A). Oleh karena itu bentuk pada sisi 
lubang (titik A) dibuat tidak berbentuk lengkungan agar konsentrasi tegangan menurun di daerah tersebut. Pemodelan lubang yang dikembangkan adalah penggambungan dua lubang dan tiga lubang seperti terlihat pada gambar 2(b) dan 2(c).

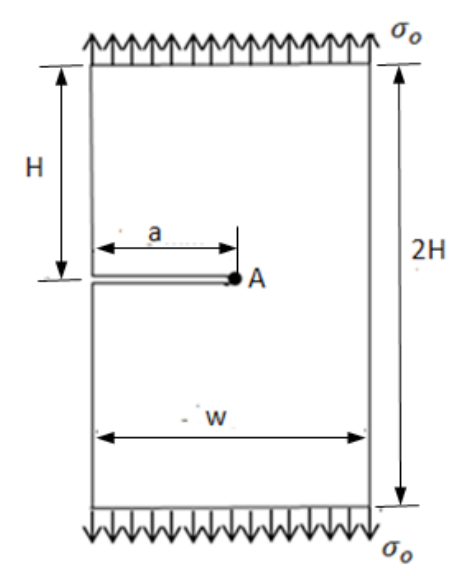

Gambar 1. Spesimen pelat

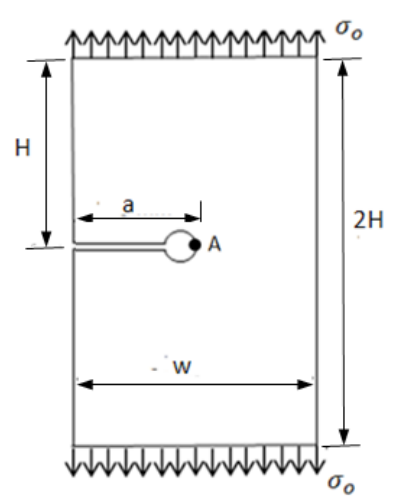

(a)

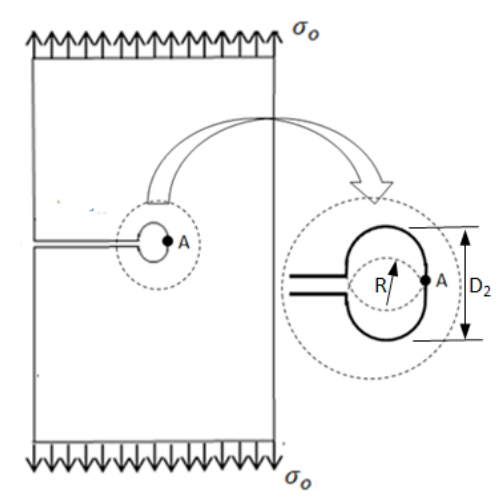

(b)

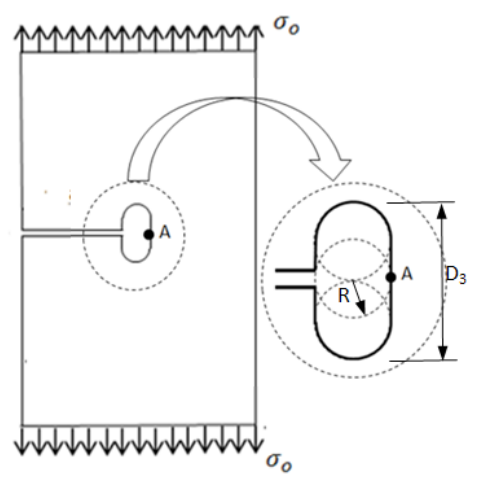

(c)

Gambar 2. Spesimen pelat model SDH: (a) Satu lubang, (b) Dua lubang, (c) Tiga lubang

Pada gambar 2 (b) dan (c) terlihat bahwa pada titik A bentuk lubang menjadi garis lurus dimana panjang atau jarak antara dua puncak lengkungan menjadi $\mathrm{D}_{2}=3 \mathrm{R}$ dan $\mathrm{D}_{3}=4 \mathrm{R}$. Perubahan bentuk lubang tersebut akan menyebabkan konsentrasi tegangan pada daerah titik A akan jauh berkurang senhingga retak tidak akan muncul pada daerah tersebut.

\section{STUDI KASUS}

Pada penelitian ini, sebuah model pelat yang digunakan mempunyai tinggi $(2 \mathrm{H})=$ $100 \mathrm{~mm}$, lebar $(\mathrm{w})=50 \mathrm{~mm}$, panjang celah $(\mathrm{a})=25 \mathrm{~mm}$, tebal $=5 \mathrm{~mm}$ dan mengalami pembebanan $\left(\sigma_{\mathrm{o}}\right)$ sebesar $10 \mathrm{MPa}$. Sementara itu, besar celah yang dimodelkan adalah 0.01 mm dimana diujung celah (titik A) dibuat tumpul dengan bentuk setengan lingakaran. Pada penelitian ini, dilakukan perbandingan faktor konsentrasi tegangan $\left(\mathrm{K}_{\mathrm{t}}\right)$ pada titik A untuk beberapa pemodelan pelat sebagai berikut:

Pelat yang tidak mempunyai lubang (hanya celah saja) seperti yang diperlihatkan pada gambar 1.

1. Pelat dengan satu lubang pada ujung retak seperti yang diperlihatkan pada gambar 2(a).

2. Pelat dengan dua lubang pada ujung retak seperti yang diperlihatkan pada gambar 2(b).

3. Pelat dengan tigs lubang pada ujung retak seperti yang diperlihatkan pada gambar 2(c).

4. Untuk pelat yang berlubang akan divariasikan besar jari-jari lubang (R), yaitu 1.25, 2.5, 
$3.75,5.0,6.25$, dan $7.5 \mathrm{~mm}$, sehingga variasi nilai D2 menjadi 3.75, 7.5, 11.25, 15.0, 18.75, dan $22.5 \mathrm{~mm}$. Sementara itu variasi nilai D3 menjadi 5.0, 10.0, 15.0, 20.0, 25.0, dan $30.0 \mathrm{~mm}$. Analisis yang dilakukan adalah kajian numerik dengan menggunakan paket program Finite Element MecWay 7. Pemodelan dengan program Finite Element dapat dilihat pada gambar 3 .

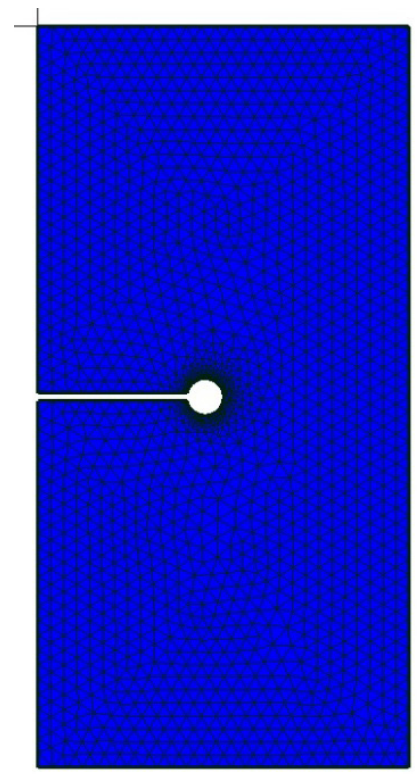

(a)

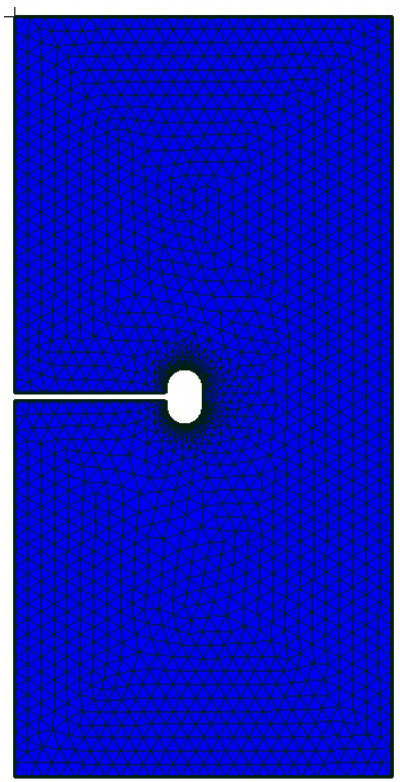

(b)

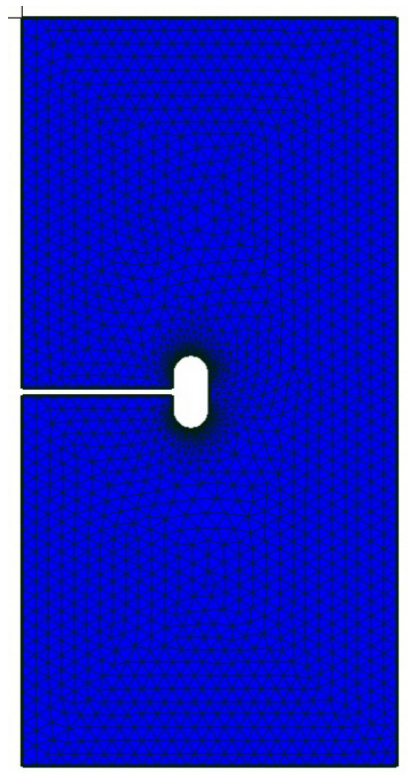

(c)

Gambar 3. Pemodelan pelat dengan Finite Element: (a) Satu lubang, (b) Dua lubang, dan (c) Tiga lubang

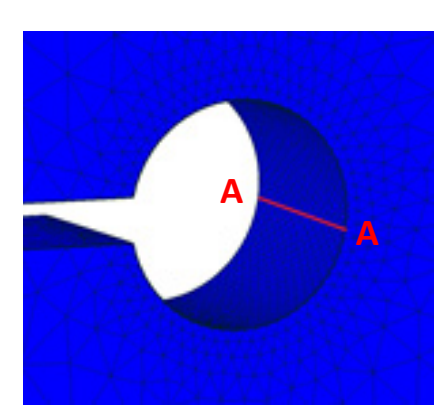

(a)

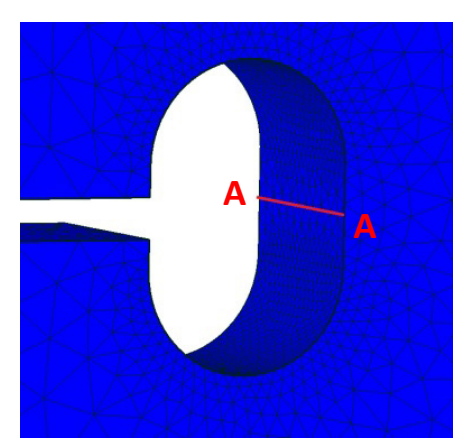

(b)

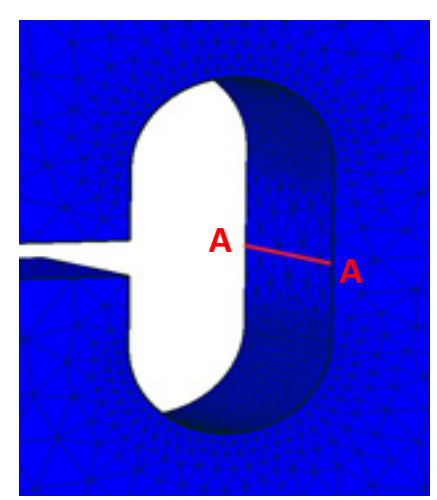

(c)

Gambar 4. Daerah yang diamalisis dengan Finite Element: (a) Satu lubang, (b) Dua lubang, dan (c) Tiga lubang

Pada gambar 4 terlihat daerah yang akan dianalisis pada penelitian ini adalah hasil penghitungan faktor konsentrasi tegangan $\left(\mathrm{K}_{t}\right)$ pada garis A untuk ketiga pemodelan.

\section{HASIL DAN PEMBAHASAN}

Pada penelitian ini, faktor konsentrasi tegangan pada ujung retak tanpa lubang akan menjadi nilai referensi. Pengaruh jumlah lubang dengan variasi nilai jari-jari terhadap faktor konsentasi tegangan $\left(\mathrm{K}_{\mathrm{t}}\right)$ pada daerah A diperlihatkan pada gambar 5. Pada gambar terlihat bahwa terjadi penurunan nilai konsentrasi tegangan dengan memberikan lubang pada ujung celah. Jumlah lubang juga memberikan pengaruh terhadap penurunan konsentrasi tegangan, 
dimana semakin banyak lubang yang diberikan maka semakin turun faktor konsentrasi tegangan. Akan tetapi untuk jumlah lubang dua dan tiga nilai konsentrasi tegangan hampir sama dengan meningkatnya nilai jari jari lubang yang diberikan. Jika dibandingan dengan nilai referensi, maka penurunan konsentrasi tegangan sangat signifikan terjadi dengan pemberian satu lubang. Penurunan nilai konsentrasi tegangan terus terjadi dengan signifikan dengan pemberian dua lubang pada ujung celah. Hal ini disebabkan oleh pindahnya konsentrasi tegangan dari daerah A seperti diperlihatkan pada gambar 6.

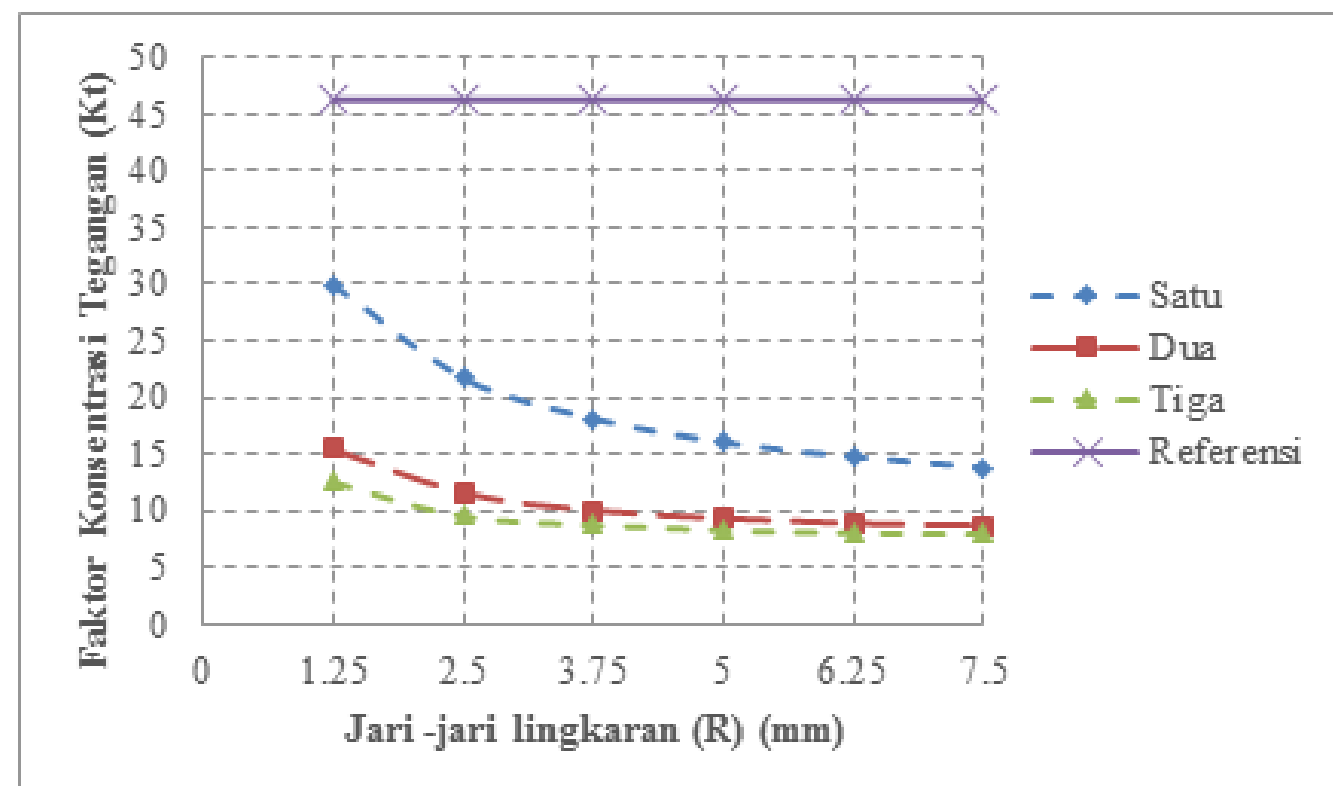

Gambar 5. Perbandingan faktor konsentrasi tegangan $\left(\mathrm{K}_{\mathrm{t}}\right)$ terhadap variasi jari-jari untuk daerah $\mathrm{A}$

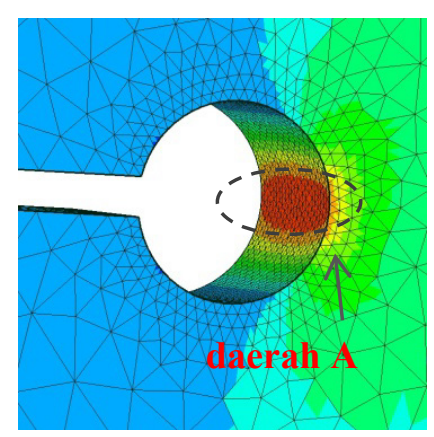

(a)

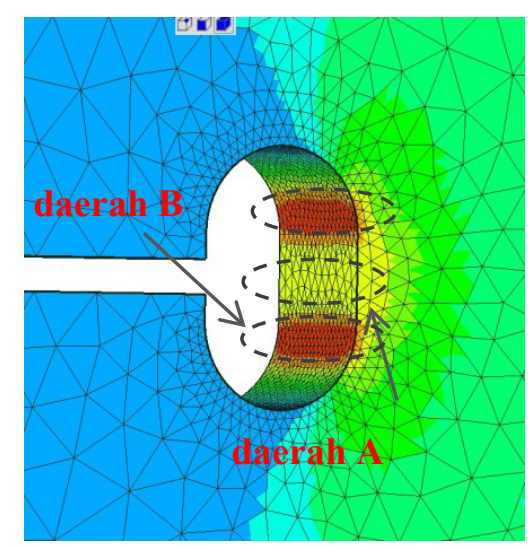

(b)

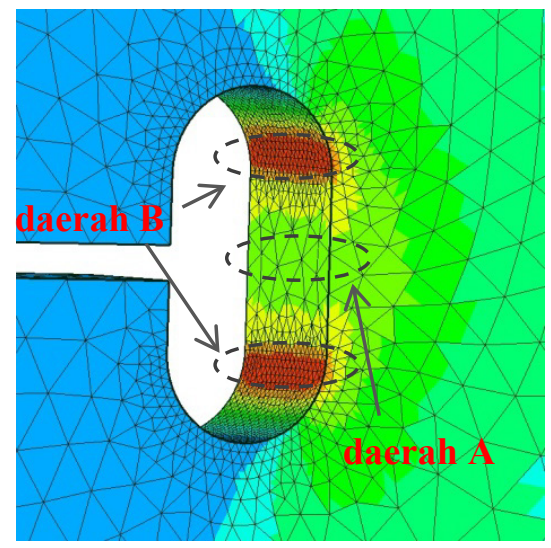

(c)

Gambar 6. Daerah konsentrasai tegangan tertinggi (a) Satu lubang, (b) Dua lubang, dan (c) Tiga lubang

Pada gambar 6 (b) dan (c) terlihat bahwa daerah konsentrasi tertinggi terletak pada daerah pertemuan garis lurus dengan kelengkungan (daerah B). Hal ini disebabkan pada daerah tersebut terjadi perubahan bentuk geometri dari lubnag sehingga menyebabkan konsentrasi tegangan tinggi di daerah tersebut. Jika konsentasi tegangan yang tinggi di daerah tersebut dibandingkan dengan konsentrasi tegangan referensi dan satu lubang, maka faktor konsentrasi tegangan tersebut masih jauh lebih rendah seperti terlihat pada gambar 7. 


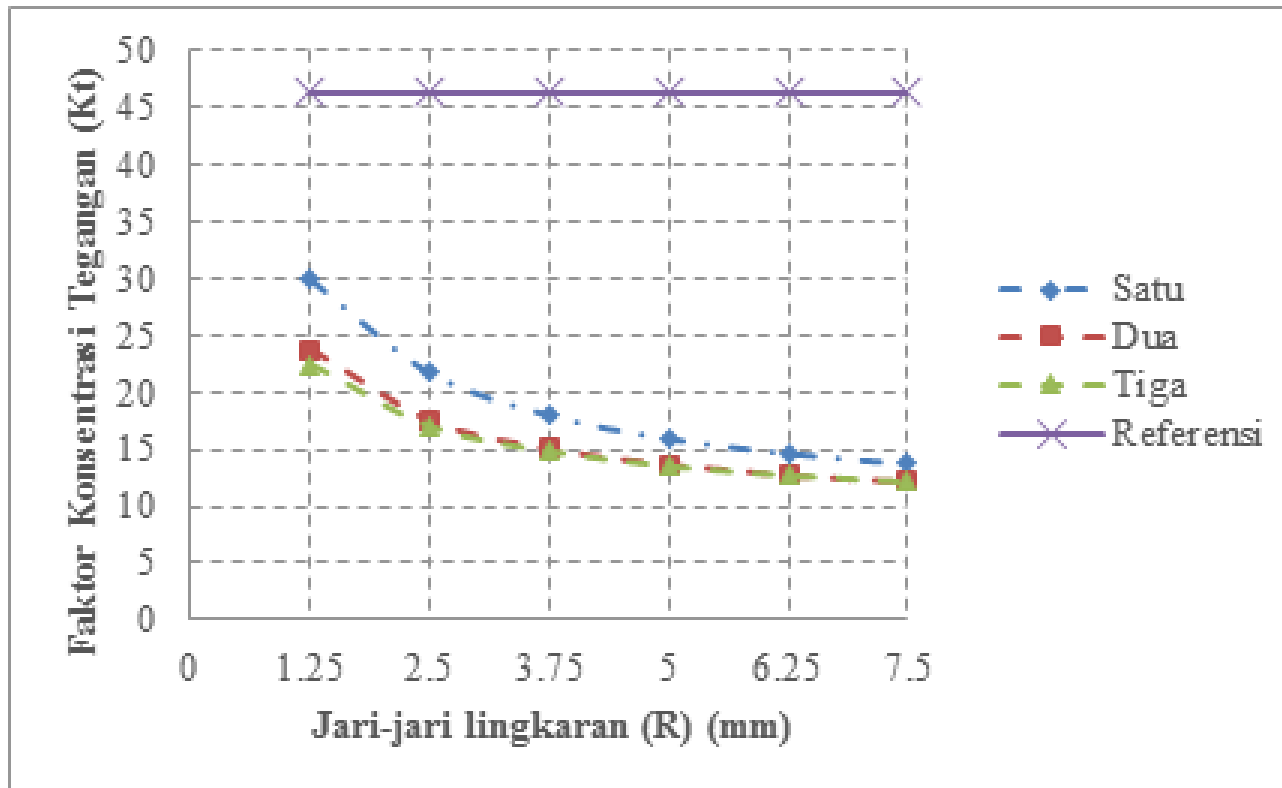

Gambar 7. Perbandingan faktor konsentrasi tegangan (Kt) terhadap variasi jari jari untuk daerah B

Pada gambar 7 terlihat bahwa faktor konsentrasi tegangan untuk lubang dua dan tiga memiliki nilai yang hampir sama, akan tetapi nilainya masih lebih rendah dari faktor konsentrasi referensi dan lubang satu. Pada gambar terlihat bahwa pemberian dua tiga lubang dapat mereduksi faktor konsentrasi tegangan meskipun tegangan yang dihitung adalah tegangan tertinggi. Selain itu dengan memperbesar jari-jari lingkaran, faktor konsentrasi tegangan cenderung turun meskipun mulai dari nilai jari-jali lingkaran $5 \mathrm{~mm}$, nilai faktor konsentrasi tegangan cenderung konstan.

\section{KESIMPULAN}

Pada penelitian yang telah dilakukan dapat disimpulkan bahwa:

1. Metode memodifikasi bentuk SDH dapat mereduksi faktor konsentrasi tegangan sehingga penjalaran retak dapat dihambat.

2. Pemberian dua lubang dan tiga lubang pada ujung cetak dapat mereduksi faktor konsentrasi tegangan dengan signifikan.

3. Nilai faktor konsentrasi tegangan antara dua lubang dan tiga lubang tidak berbeda signifikan terutama dengan meninggkatnya nilai jari-jari lubang.

4. Konsentrasi tegangan tetinggi terjadi pada daerah perubahan geometri pada lubang untuk pemberian dua atau tiga lubang, akan tetapi faktor konsentrasi tegangannya masih cukup rendah jika dibandingkan dengan pemberian satu lubang pada ujung celah.

\section{UCAPAN TERIMA KASIH}

Penulis mengucapkan terimakasih pada Jurusan Teknik Mesin, Universitas Andalas atas bantuan biaya pada Skim Penelitian Jurusan Teknik Mesin 2017.

\section{DAFTAR PUSTAKA}

[1] Song PS, Shieh YL. 2004. Stop Drilling Procedure for Fatigue Life Improvement. International Journal of Fatigue, 26, pp. 1333-1339.

[2] Murdani A., Macabe C., Saimoto A., Kondo R. 2008. A Crack Growth Arresting Technique in Aluminum Alloy. Engineering Failure Analysis, 15, pp. 302-310. 
[3] T. Nateche T., Hadj Meliani M., Matvienko Y.G., Pluvinage G., 2016, Drilling Repair Index (DRI) Based on Two-Parameter Fracture Mechanics for Crack Arrest Holes, Engineering Failure Analysis, 59, pp. 99-110.

[4] Macabe C., Murdani A., Kuniyoshi K., Irei Y., Saimoto A., 2009. Crack - Growth Arrest by Redirecting Crack Growth by Drilling Stop Holes and Inserting Pins into Them. Engineering Failure Analysis, 16, pp. 247-483.

[5] S.M.J. Razavi S. M. J., Ayatollahi M. R., Sommitsch C., Moser C., 2017, Retardation of Fatigue Crack Growth in High Strength Steel S690 Using A Modified Stop-Hole Technique, Engineering Fracture Mechanics, 169, pp. 226-237. 